University of Nebraska - Lincoln

DigitalCommons@University of Nebraska - Lincoln

\title{
Application of a strip-yield model to predict crack growth under variable-amplitude and spectrum loading - Part 1: Compact specimens
}

\author{
Y. Yamada \\ Ohio Aerospace Institute at NASA Glenn Research Center \\ B. Ziegler \\ Mississippi State University \\ J.C. Newman Jr. \\ Mississippi State University, j.c.newman@ae.msstate.edu
}

Follow this and additional works at: https://digitalcommons.unl.edu/nasapub

Part of the Physical Sciences and Mathematics Commons

Yamada, Y.; Ziegler, B.; and Newman, J.C. Jr., "Application of a strip-yield model to predict crack growth under variable-amplitude and spectrum loading - Part 1: Compact specimens" (2011). NASA Publications. 99.

https://digitalcommons.unl.edu/nasapub/99

This Article is brought to you for free and open access by the National Aeronautics and Space Administration at DigitalCommons@University of Nebraska - Lincoln. It has been accepted for inclusion in NASA Publications by an authorized administrator of DigitalCommons@University of Nebraska - Lincoln. 


\title{
Application of a strip-yield model to predict crack growth under variable-amplitude and spectrum loading - Part 1: Compact specimens
}

\author{
Y. Yamada ${ }^{\text {a }}$, B. Ziegler ${ }^{\text {b }}$, J.C. Newman Jr. ${ }^{\text {b,* }}$ \\ ${ }^{a}$ Ohio Aerospace Institute at NASA Glenn Research Center, Cleveland, $\mathrm{OH} 44135$, USA \\ ${ }^{\mathrm{b}}$ Mississippi State University, Aerospace Engineering, Mississippi State, MS 39762, USA
}

\section{A R T I C L E I N F O}

\section{Keywords:}

Cracks

Fatigue-crack growth

Aluminum alloy

Crack closure

Stress-intensity factor

Plasticity

\begin{abstract}
A B S T R A C T
Fatigue-crack-growth tests were conducted on compact, $C(T)$, specimens made of $\mathrm{D} 16 \mathrm{Cz}$ (clad) aluminum alloy under constant-amplitude loading, a single spike overload, and simulated aircraft spectrum loading. Constant-amplitude tests were conducted to generate crack-growth-rate data from threshold to near fracture over a wide range of stress ratios $\left(R=P_{\min } / P_{\max }=0.1-0.75\right)$ using the new compression pre-cracking test methods. Comparisons were made between test data generated on the $C(T)$ specimens with test data from the literature on middle-crack-tension, $M(T)$, specimens machined from the same sheet. A crack-closure analysis was used to collapse the rate data from both specimen types into a narrow band over many orders of magnitude in rates using proper constraint factors. The constraint factors were established from constant-amplitude (CA) and single-spike overload tests. The life-prediction code, FASTRAN, which is based on the strip-yield model concept, was used to calculate crack-length-against-cycles under CA loading and a single-spike overload (OL) test, and to predict crack growth under simulated aircraft spectrum loading tests on $C(T)$ specimens. The calculated crack-growth lives under CA loading were generally within about $\pm 25 \%$ of the test results, but slower crack growth under the double-shear fatigue mode, unlike the single-shear mode ( $45^{\circ}$ slant crack growth), may be the reason for some of the larger differences. The predicted results under the single-spike overload and the Mini-Falstaff+ spectrum were within $10 \%$ of the test data.
\end{abstract}

(c) 2011 Elsevier Ltd. All rights reserved.

\section{Introduction}

In 2004, Schijve et al. [1] presented the results of various fatigue-crack-growth-rate tests on the aluminum alloy D16Cz (clad) sheet, which was considered to have crack-growth properties similar to the 2024-T3 alloy. Later, these test results were compared to calculations made with the NASGRO [2] life-prediction code by Skorupa et al. [3]. In the NASGRO calculations, the strip-yield model options were used. In the mid-1990s, the strip-yield model options in NASGRO were developed by the National Aerospace Laboratory [4] in a joint effort between the European Space Agency and the National Aeronautics and Space Administration. The model equations were similar to those developed in the FASTRAN life-prediction code [5], which are based on Elber's crack-closure concept [6] and the Dugdale strip-yield model [7]. The NASGRO code has two strip-yield model options: (1) variable constraint in the plastic-zone region, and (2) constant constraint in the plastic-zone region. Both options were used and the article stated that "no analysis option enabled to reproduce crack growth retardation observed after application of a single overload cycle ... Improving the predictions for variable-amplitude (VA) loading would require

\footnotetext{
* Corresponding author. Tel.: +1 662325 1521; fax: +1 6623257720 .

E-mail address: j.c.newman@ae.msstate.edu (J.C. Newman Jr.).
} 


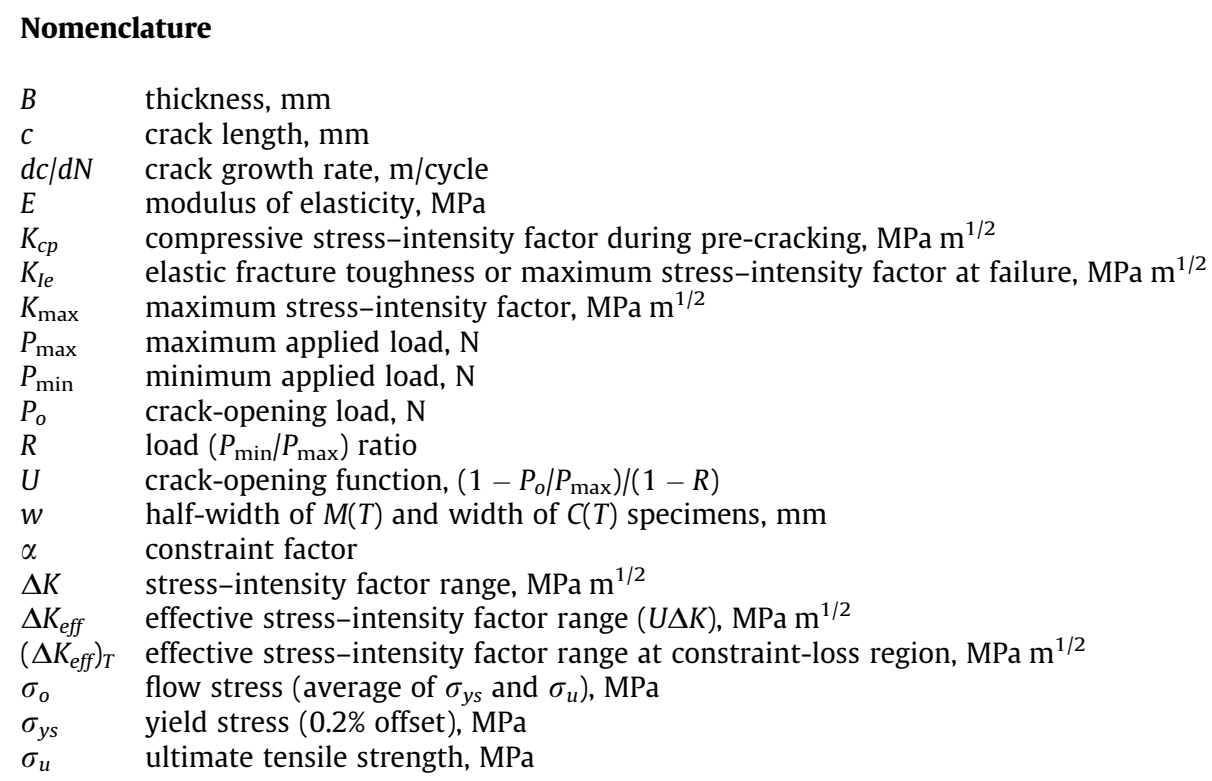

choosing lower values of the fitting parameter $(\alpha)$ which, however, would worsen the predictions for constant-amplitude (CA) loading" [3]. The unexpected inconsistencies found in these comparisons and the emphasis on the constraint-loss regime has inspired the present work.

Using material provided by the research group in Poland (M. Skorupa and T. Machniewicz, University of Science and Technology), a series of fatigue-crack-growth tests were performed on compact, $C(T)$, specimens machined from previously fractured middle-crack tension, $M(T)$, specimens. Testing included constant-amplitude (CA) loading at several stress ratios $(R)$, a single-spike overload test, and spectrum tests using Mini-Falstaff+, a spectrum derived from Mini-Falstaff [8,9] consisting of only tensile loads. Test data generated under CA loading on the $C(T)$ specimens were combined with the test data by Schijve et al. [1] on $M(T)$ specimens to develop a multi-linear curve describing the relationship between crack-growth rate $(d c / d N)$ and the effective stress-intensity factor $\left(\Delta K_{\text {eff }}\right)$ using proper constraint factors. The constraint factor models the elevation of the flow stress around a crack front due to the tri-axial stress state $[10,11]$. The constraint factor $(\alpha)$ is a key parameter in the correlation of fatigue-crack-growth-rate data and the prediction of crack growth under variable-amplitude loading. It was determined many years ago that CA test data was necessary, but not sufficient to establish the constraint factors $[12,13]$. Single-spike or repeated-spike overload tests are more sensitive to constraint factors than CA loading. It would be prudent to conduct tests under spike overloads or other VA loading to validate the selection of the constraint factors. Of course, the $C A$ tests at various stress ratios $(R)$ may be used to estimate an initial value of the constraint factor. In addition, a constraintloss regime (transition from plane strain to plane stress) [14] occurs as the plastic-zone size approaches the sheet thickness, that allows slip-bands to develop through the thickness, and the crack surfaces develop full slant (single shear) or doubleshear fracture $[15,16]$.

This research work is organized in two papers. The objectives of the first paper were to present test data on compact, $C(T)$, specimens, to develop the effective stress-intensity factor against rate relation, and to determine the proper constraint factors for the D16Cz alloy. While the objectives of the second paper [17] were to present test data on the $M(T)$ specimens [1] and to predict crack growth under a single-spike overload, variable-amplitude (block) loading, and the Mini-Falstaff spectrum loading. Herein, the FASTRAN life-prediction code was used to calculate the crack length against cycles for the $C(T)$ specimens under CA loading, a single-spike overload (OL) and, finally, the code was used to predict the crack length against cycles on two spectrum tests. The following will present and discuss the specifics of the material, specimens tested, test data analyses, types of fatigue loading applied, the crack-growth analyses performed and a comparison of test and analyses.

\section{Material}

The material used was the Russian alloy D16CzATWH, which appears to be similar to the American alloy 2124. It is a high purity clad alloy. Tensile testing performed by Schijve et al. [1] determined the mechanical properties to be $\sigma_{y s}=335 \mathrm{MPa}$, $\sigma_{u}=457 \mathrm{MPa}$ and an elongation of $22 \%$. The high elongation (as compared to 2024-T3) is likely explained by the low impurity content (Fe and $\mathrm{Si}$ ) and the crack-growth properties are considered to be similar to the 2024-T3 alloy [1]. 


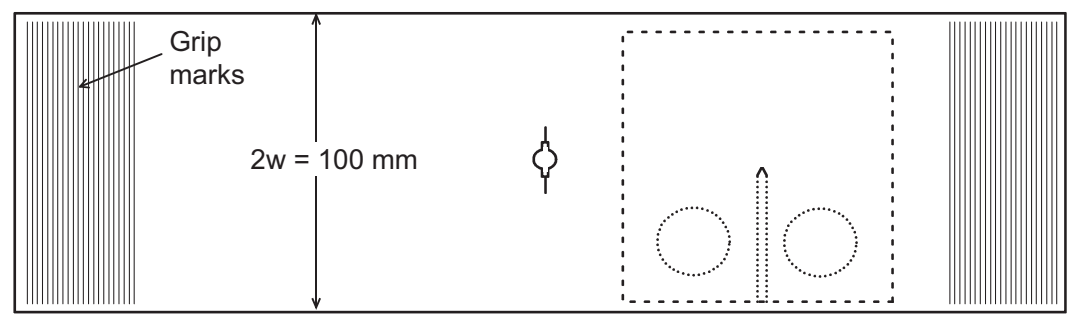

(a) Middle-crack-tension specimen

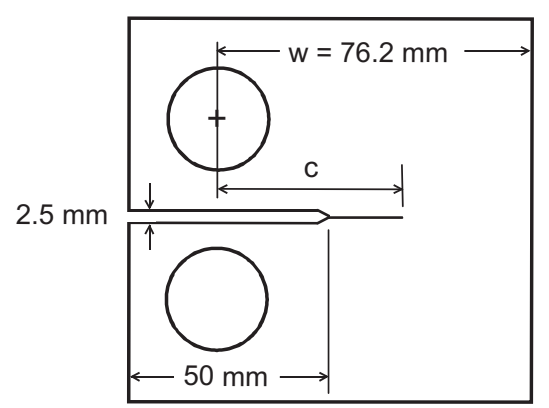

(b) Compact specimen

Fig. 1. Layout and dimensions of $C(T)$ specimen cut from $M(T)$ specimen.

\section{Specimens}

The material used in the current study was obtained from the research group in Poland (M. Skorupa and T. Machniewicz, University of Science and Technology). They had conducted crack-growth tests on $M(T)$ specimens (Fig. 1) made of the D16Cz alloy and had provided the current authors with 9 broken halves of some specimens. The sheet thickness was $B=4 \mathrm{~mm}$. From these broken halves, nine $C(T)$ specimens were machined, as shown in Fig. $1 \mathrm{~b}$. The applied stresses in the middle of the $M(T)$ specimens would always be elastic and it would not be expected that elastic cycling would affect the crack-growth properties of the material. Also, it was not known from the Schijve et al. [1] and Skorupa et al. [3] papers nor the current study whether residual stresses were present in the material before testing.

Standard ASTM plan-form $C(T)$ specimens were machined from the broken halves of a number of previously tested $M(T)$ specimens in the as-received thickness. Most $C(T)$ specimens came from only one half of an $M(T)$ specimen, however, there were two $C(T)$ specimens machined from one specimen. Due to the loss in luster experienced during the machining process, the specimens were once again polished to $1-\mu \mathrm{m}$ to facilitate visual crack measurement. Specimens were polished on only one side causing a slight reduction in the thickness of the cladding layer on one side of the specimens. To initiate a crack, a $45^{\circ} \mathrm{V}$-notch with a tip radius less than $0.1 \mathrm{~mm}$ was electrical-discharge-machined (EDM) into all $C(T)$ specimens. Tests were conducted on the $76.2 \mathrm{~mm} C(T)$ specimens over a range of stress ratios $(R)$, a single-spike overload, and under a simulated aircraft spectrum loading.

\section{Testing}

Fatigue-crack-growth-rate data under CA loading were obtained from the literature on $M(T)$ specimens made of the D16Cz alloy [1]. All $C(T)$ tests were conducted at Mississippi State University on a $25 \mathrm{kN}$ servo-hydraulic load frame operated through the aid of a steady-state and variable-amplitude fatigue-crack-growth software. These tests were conducted under laboratory air and at room temperature. Crack lengths were measured visually with a traveling microscope and with a backface strain gage. The back-face strain gage was used with a compliance relation that enabled the software to automatically monitor crack lengths during the fatigue-crack-growth tests.

\subsection{Constant-amplitude loading}

The CA tests on the $M(T)$ specimens were performed by Schijve et al. [1] at different stress ratios $(R)$ varying between $R=-0.5-0.75$. All CA tests were conducted at a frequency of $15 \mathrm{~Hz}$ [1].

CA testing on the $C(T)$ specimens was achieved at a frequency of $18 \mathrm{~Hz}$. Compression pre-cracking threshold testing procedures [18-21] were used to generate very low fatigue-crack-growth rates without possible load-history effects from using the current ASTM load-reduction procedure [22]. All specimens were subjected to compressive pre-cracking at 
$P_{\text {min }}=-3.3 \mathrm{kN}\left(K_{c p}=-23 \mathrm{MPa} \mathrm{m}^{1 / 2}\right)$ with $R=7.5$ before applying the primary loading. Three of the tests were compression pre-cracked load reduction (CPLR) tests at $R=0.75,0.33$ and 0.1. The CPLR loading sequence is shown in Fig. 2a. After compression pre-cracking for about 60,000 cycles, the crack would naturally stop growing. Then CA loading was applied to grow the crack about 3 compressive plastic-zone sizes (effects of tensile residual stresses due to compressive yielding would have dissipated and the crack-closure behavior would have stabilized [20]). At this point, it was possible to begin a load-reduction scheme, per ASTM E-647 procedures [22], that provided data at rates approaching threshold. (Note: The load-reduction scheme was initiated at a crack-growth rate much lower than the maximum rate allowed by the standard or could be achieved by CA loading only.) In addition, two tests were conducted using the compression pre-cracked constant-amplitude (CPCA) method at both $R=0.1$ and 0.33 , as shown in Fig. 2b. These tests involved starting with the compression pre-cracked specimen and then applying very low $\Delta K$ values until the crack grew. When it became apparent that rates were slowing down and approaching a threshold, the load was slightly increased. This process continued until steady crack growth was achieved. The five tests produced crack-growth-rate data ranging from threshold to near fracture.

\subsection{Single-spike overload}

A single-spike OL test was performed on a $C(T)$ specimen to help establish the constraint factors and to verify the ability of the FASTRAN code to account for crack-growth acceleration and delayed retardation after the OL. CA loading $(R=0.1)$ was applied until the crack length had reached $40 \mathrm{~mm}$. Then an OL of twice $P_{\max }$ was manually applied. The OL was removed and the CA loading was applied until sufficient crack growth had occurred to ensure that the effects of the OL had dissipated. This specimen was then monotonically loaded to failure to gain information about the fracture toughness.

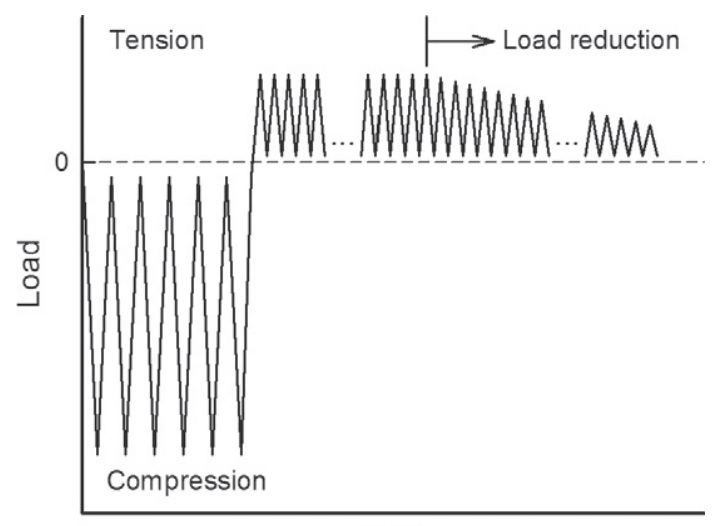

Time

(a) Compression precracking load reduction

(CPLR) loading sequence.

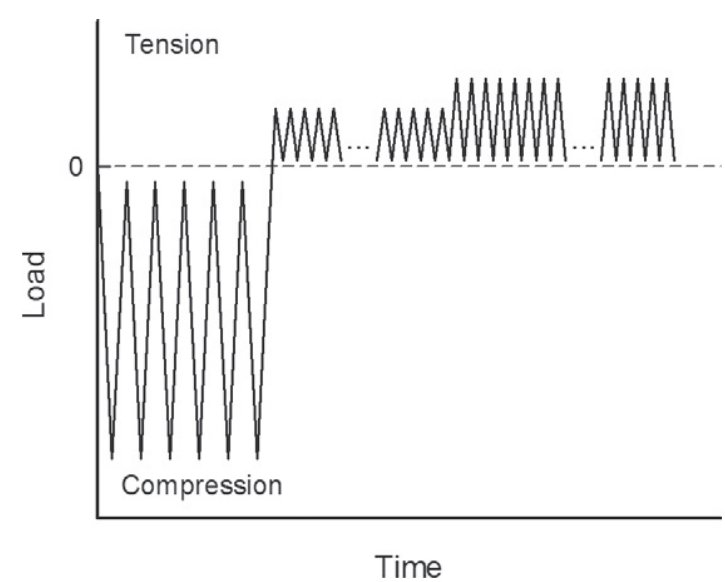

(b) Compression precracking constantamplitude (CPCA) loading sequence.

Fig. 2. Load sequences used for threshold and constant-amplitude testing. 


\subsection{Spectrum loading}

In Schijve et al. [1], the fighter spectrum (Mini-Falstaff) was applied to $M(T)$ specimens at various maximum applied stress levels. The Mini-Falstaff sequence has 9006 cycles, which is equivalent to 200 flights [8,9]. In view of the random sequence of small and large load amplitudes, the tests were conducted with an approximately constant loading rate. As a result, one period of 9006 cycles occurred in about 38 min (corresponds to an average frequency of $4 \mathrm{~Hz}$ ) [1].

Limitations inherent in $C(T)$ specimens made it very difficult to use Mini-Falstaff loading, because of the compressive loads. Instead, a similar spectrum was created to verify the effectiveness of FASTRAN to predict crack growth under a similar spectrum loading. The spectrum, Mini-Falstaff+, was derived from the Mini-Falstaff spectrum using Eq. (1). Mini-Falstaff loads are converted to Mini-Falstaff+ loads by

$$
\text { Mini-Falstaff }+=(\text { Mini-Falstaff }+0.3667) / 1.3667
$$

This ensured that the maximum normalized load in the sequence is unity and the minimum normalized load is one-tenth, removing the compressive loads entirely. Some of the Mini-Falstaff+ sequence is shown in Fig. 3. The Mini-Falstaff+ spectrum was applied to the specimens at a constant load rate, which produced an average frequency of $3 \mathrm{~Hz}$ (about 50 min per 9006 cycles). Mini-Falstaff+ tests were conducted at peak loads of $1.8 \mathrm{kN}$ and $2.8 \mathrm{kN}$.

\section{FASTRAN - plasticity-induced crack-closure model}

The plasticity-induced crack-closure model was developed for a central through crack and two-symmetric through cracks emanating from a circular hole in a finite-width plate subjected to uniform remote applied stress. The model was based on Elber's crack-closure concept [6] and the Dugdale strip-yield model [7], but modified to leave plastically deformed material in the wake of the crack. The details of the model are given elsewhere and will not be presented here (see Newman [10,11]). One of the most important features of the model is the ability to model three-dimensional constraint effects. A constraint factor $\alpha$ is used to elevate the flow stress $\left(\sigma_{o}\right)$ at the crack tip to account for the influence of stress state $\left(\alpha \sigma_{o}\right)$ on plastic-zone sizes and crack-surface displacements. (The flow stress $\sigma_{o}$ is taken as the average between the yield stress $\sigma_{y s}$ and ultimate tensile strength $\sigma_{u}$ of the material. Whenever possible, the cyclic stress-strain curve should be used.) For plane stress conditions, $\alpha$ is equal to unity (original Dugdale model); and for simulated plane strain conditions, $\alpha$ is equal to 3 . The calculations performed herein were made with FASTRAN Version 3.82.

\subsection{Effective stress-intensity factor range}

For most damage-tolerance and durability analyses, linear-elastic fatigue-crack-growth analyses have been found to be quite adequate. Thus, the effective stress-intensity factor range [6] is

$$
\Delta K_{\text {eff }}=\left(S_{\max }-S_{0}\right) \sqrt{(\pi c)} F
$$

where $S_{\max }$ is the maximum stress, $S_{o}$ is the crack-opening stress and $F$ is the boundary-correction factor. The boundarycorrection factor accounts for the configuration (boundaries, holes) on stress-intensity factors. In general, $S_{o}$ is calculated from the FASTRAN code [5], but for steady-state constant-amplitude loading, the crack-opening stress can be calculated from closed-form equations [11].

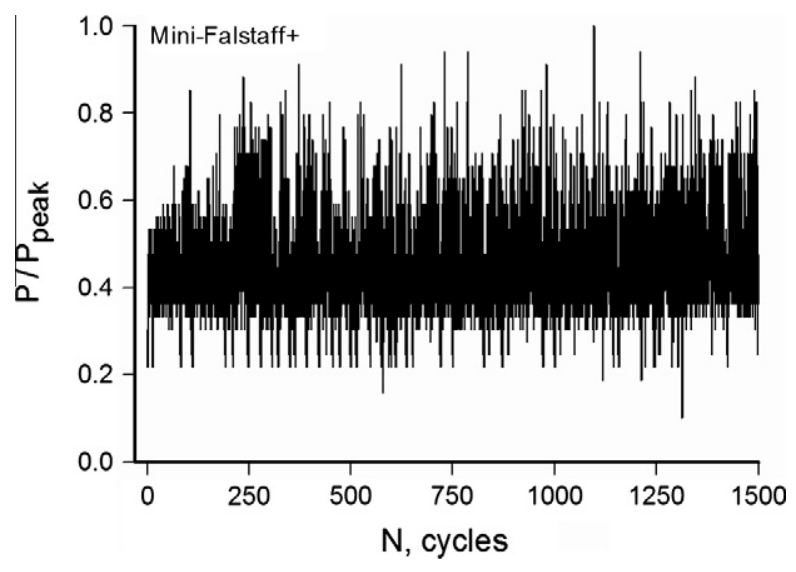

Fig. 3. Mini-Falstaff + spectrum loading sequence. 


\subsection{Constant-amplitude loading}

Newman [11] developed steady-state crack-opening stress equations from the plasticity-induced crack-closure model for a middle-crack tension $M(T)$ specimen subjected to CA loading at various stress levels, stress ratios $(R)$, and constraint factors $(\alpha)$. Crack-closure transients, before the crack-opening stresses stabilize under CA loading, are not included in these equations. The FASTRAN model has to be exercised to determine these transient behaviors. Later, the FASTRAN model and the equations were modified to account for extreme crack-growth rates, such as those under high loads or proof testing. Equations were then fit to the results from the model, which gave crack-opening stress $\left(S_{o}\right)$ as a function of stress ratio $(R)$, maximum stress level $\left(S_{\max } / \sigma_{o}\right)$, the constraint factor $(\alpha)$, and the amount of crack growth during a cycle [11,14]. Since the crack-opening stress equation was developed for an $M(T)$ specimen, $K$-analogy [23] is used to calculate the crack-opening stresses for other crack configurations, such as the $C(T)$ specimen. Here it is assumed that the same $K_{\text {max }}$ and $\Delta K$ will result in the same stabilized crack-opening stress. These equations are then used to correlate fatigue-crack-growth-rate data in terms of $\Delta K_{\text {eff }}$ on $M(T)$ and $C(T)$ specimens.

\subsection{Constraint effects}

In general, the plastic-zone size at the crack front increases as a crack grows in a metallic material under cyclic loading (constant applied cyclic stresses). At low stress-intensity factor levels, plane-strain conditions should prevail, but as the plastic-zone size becomes large compared to thickness, a loss of constraint is expected. This constraint loss has been associated with the transition from flat-to-slant crack growth. Schijve [15] has shown that the transition occurs at nearly the same fatigue-crack-growth rate over a wide range of stress ratios for an aluminum alloy. Since Elber's concept [6] correlates fatigue-crack-growth rates, then the transition should also occur at the same $\Delta K_{\text {eff. }}$ This observation has been used to help select the constraint-loss regime. Newman [14] developed an expression to predict the full transition from flat-to-slant crack growth and the $\Delta K_{\text {eff }}$ at transition is given by

$$
\left(\Delta K_{\text {eff }}\right)_{T}=0.5 \sigma_{0} \sqrt{B}
$$

where $\sigma_{o}$ is the flow stress and $B$ is the material thickness. The range of the constraint-loss regime, in terms of rate or $\Delta K_{e f f}$, is a function of thickness, but this relation has yet to be developed. Trial-and-error methods are currently used to establish the range in crack-growth rates where the constraint-loss regime will occur for a given material and thickness.

In the application of FASTRAN, the constraint-loss regime is controlled by crack-growth rates. For rates lower than a certain (input) value, the constraint factor is high (like plane strain), but if the rate is higher than another (input) rate, then the constraint factor is low (like plane stress). For intermediate rates, a linear relation on log of rates is used to estimate the constraint factor between the upper and lower constraint values. The constraint factor only changes the forward plastic-zone size and crack-surface displacements under the current loading. The crack-growth model does "not" physically model the shear-lip or slant crack-growth process under either constant- or variable-amplitude loading. Obviously, the crack-growth process under variable-amplitude loading is quite complex and the FASTRAN model is a simple engineering approximation.

\subsection{Crack-growth-rate relation}

The crack-growth relation used in FASTRAN is a multi-linear relation with terms to account for threshold and fracture, and is

$$
d c / d N=C_{1 i}\left(\Delta K_{\text {eff }}\right)^{C_{2 i}}\left[1-\left(\Delta K_{o} / \Delta K_{\text {eff }}\right)^{p}\right] /\left[1-\left(K_{\max } / K_{\text {Ie }}\right)^{q}\right]
$$

where $C_{1 i}$ and $C_{2 i}$ are the coefficient and power for each linear segment, $\Delta K_{\text {eff }}$ is the effective stress-intensity factor, $\Delta K_{o}$ is the effective threshold, $K_{\max }$ is the maximum applied stress-intensity factor, $K_{I e}$ is the elastic fracture toughness (which is, generally, a function of crack length, specimen width, and specimen type), $p$ and $q$ are constants selected to fit test data in either the threshold or fracture regimes. Whenever the applied $K_{\max }$ value reached or exceeded $K_{I e}$, then the rate would go to infinity and the specimen or component would fail. Herein, $\Delta K_{o}$ was set to zero and the threshold behavior was modeled with multi-linear segments and the threshold behavior was assumed to be independent of $R$. (Recently, measurements of crack-opening loads in the near-threshold regime for a wide range in $R$ values and $K_{\max }$ test conditions on an aluminum alloy have shown that $\Delta K_{\text {eff }}$ correlates crack-growth rate data in the threshold regime quite well [24].) The multi-linear form is used instead of the sigmoidal form because many materials, especially aluminum alloys, show sharp changes in the crack-growth-rate curves at unique values of rates.

\subsection{Fracture}

Newman [25] proposed the Two-Parameter Fracture Criterion (TPFC) to correlate fracture data and to predict failure loads on cracked metallic materials. The TPFC equation is

$$
K_{F}=K_{I e} /\left\{\left(1-m S_{n} / S_{u}\right)\right\} \text { for } S_{n}<\sigma_{y s}
$$


where $K_{F}$ and $\mathrm{m}$ are the two fracture parameters, $K_{I e}$ is the elastic fracture toughness (elastic stress-intensity factor at failure), $S_{n}$ is the net-section stress and $S_{u}$ is the plastic-hinge stress based on the ultimate tensile strength. For example, for an $M(T)$ specimen $S_{u}$ is equal to $\sigma_{u}$, the ultimate tensile strength; for a pure bend specimen, $S_{u}=1.5 \sigma_{u}$; and for a $C(T)$ specimen, $S_{u} \approx 1.62 \sigma_{u}$. A similar equation was derived for $S_{n}>\sigma_{y s}$, see Ref. [25]. The $m$-value is both a material and configuration parameter. It is a function of material, thickness, and, in general, specimen type (tension, bending, etc.). For brittle materials, $m=0$ and the fracture toughness $K_{F}$ is equal to the elastic stress-intensity at failure (like, $K_{I c}$, the plane-strain fracture toughness). However, for very ductile materials, $m=1$ and the fracture toughness $K_{F}$ is the elastic-plastic fracture toughness; and $K_{F}$ is the largest limiting value for very large cracked panels and at very low failure stresses. For $m=1$ and a very large $K_{F}$ value, Eq. (5) reduces to a net-section-stress-equal-plastic-hinge-stress (limit-load) failure criterion based on the ultimate tensile strength. Once $K_{F}$ and $\mathrm{m}$ are known for a material, thickness, and specimen configuration, then the $K_{I e}$ values can be calculated as

$$
K_{I e}=K_{F} /\left\{1-m K_{F} /\left[S_{u} \sqrt{(\pi c)} F_{n}\right]\right\} \quad \text { for } S_{n}<\sigma_{y s}
$$

for a given crack length and specimen width. (Note that $F_{n}$ is the usual boundary-correction factor, $F$, on the stress-intensity factor with a net-to-gross section conversion [25], because the net-section stress is used in Eq. (6).) For $S_{n}>\sigma_{y s}$, a more complicated equation, which is a function of the stress-strain curve, is given in Ref. [25].

Fig. 4 shows $K_{I e}$ against crack-length-to-width $\left(c_{i} / w\right)$ ratio for $C(T)$ specimens. The symbols show the fracture test data on the $\mathrm{D} 16 \mathrm{Cz}$ alloy. Most specimens were fatigued to failure, but one specimen was fatigued and then monotonically pulled to failure (solid circle). These results show that $K_{I e}$ is a function of crack length. Also, larger width specimens produce larger $K_{I e}$ values at failure for the same crack-length-to-width ratio (not shown), and the $K_{I e}$ values approach zero as the crack length approaches the specimen width. The fracture toughness, $K_{F}$ was found to be $250 \mathrm{MPa} \mathrm{m}^{1 / 2}$ and $m=1.0$ for the D16Cz alloy. The TPFC (solid curve) fit the test data very well for the $C(T)$ specimens. The dashed curve shows the calculated $K_{I e}$ values for the 2024-T3 alloy [25]. For years, the transferability of fracture properties from bend- to tension-loaded crack configurations has been a concern of the fracture community. For the 2024-T3 alloy, the same values of $K_{F}$ and m have also been used to predict failure on $M(T)$ specimens [25]. Thus, the same values of $K_{F}$ and $\mathrm{m}$ for the D16Cz alloy are assumed to apply for $M(T)$ specimens.

\section{Constant-amplitude loading}

The $\Delta K$-rate data from both $C(T)$ and $M(T)$ [1] specimens are shown in Fig. 5 over a wide range of rates and stress ratios. (Note that $\Delta K$ is full range for the $R=-0.5$ test.) The solid curve is the $\Delta K_{\text {eff }}$-rate relation for 2024-T3 bare aluminum alloy [14]. The $C(T)$ and $M(T)$ data at $R=0.75$ agreed well with each other and also agreed with the 2024-T3 curve. Of concern was the rapid transition in the $\Delta K$-rate data in the range of $5 \mathrm{e}-9$ to $5 \mathrm{e}-8 \mathrm{~m} /$ cycle for $R=0.1$ and 0.33 . Because of this behavior, two duplicate tests were conducted at the two low $R$ ratios to verify the existence of the rapid transition.

To make crack-growth predictions, $\Delta K_{\text {eff }}$ as a function of the crack-growth rate must be obtained over the widest possible range in rates (from threshold to fracture), especially if spectrum loading predictions are required. Under CA loading, the only unknown in the analysis is the constraint factor, $\alpha$. Assuming that the $R=0.75$ test is a fully-open crack, i.e. $\Delta K_{\text {eff }}=\Delta K$, the $\Delta K$-rate data at the other $R$ values can be used to find a constraint factor that would match the low- and high- $R$ data on a $\Delta K_{\text {eff }}$ basis. A crack-opening ratio was found for each test data point ( $\Delta K$-rate for $d c / d N<1 \mathrm{e}-7 \mathrm{~m} / \mathrm{cycle}$ ) to match a best-fit curve to the high- $R$ data. These results are shown in Fig. 6 . Here the $P_{o} / P_{\max }$ ratio is plotted against the stress ratio. The solid

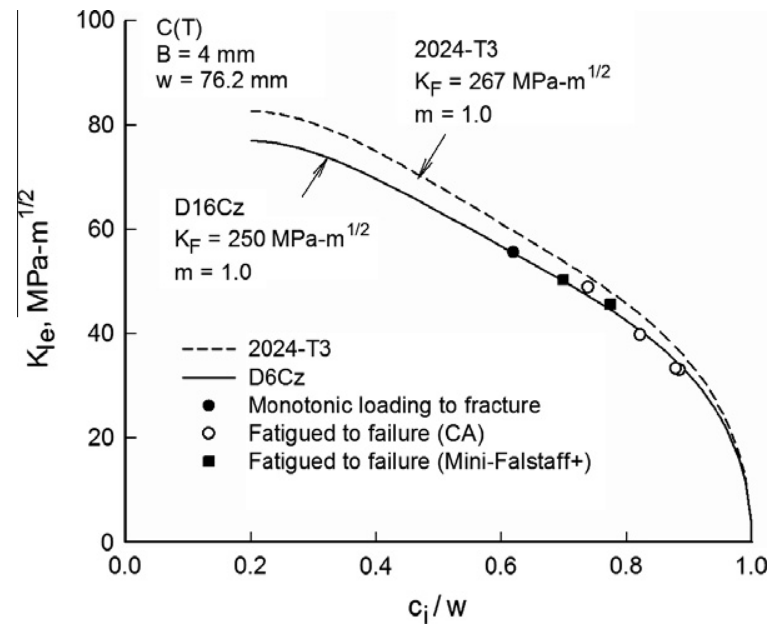

Fig. 4. Elastic stress-intensity factor at failure on $C(T)$ specimens. 


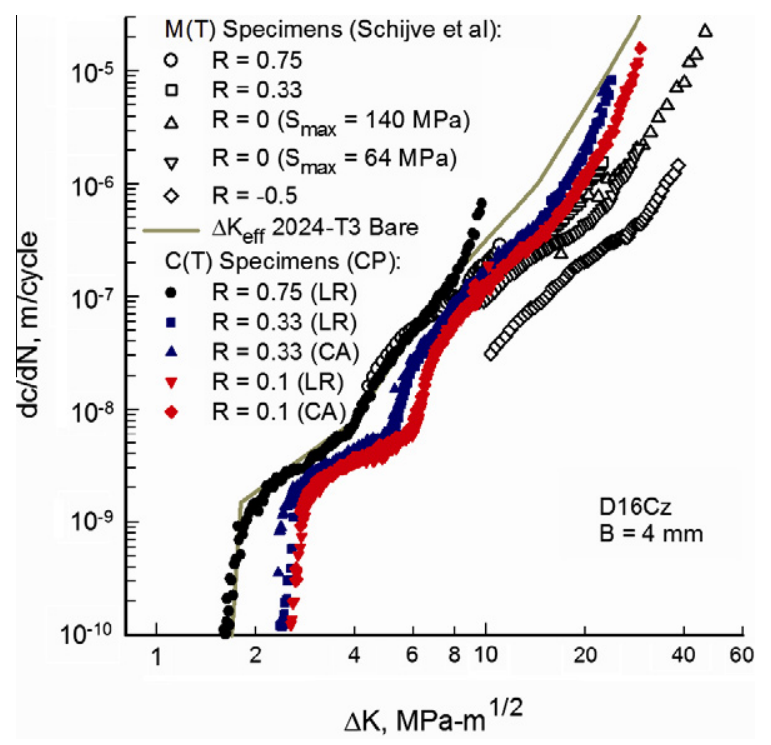

Fig. 5. LEFM $\Delta K$ against rate for $C(T)$ and $M(T)$ specimens.

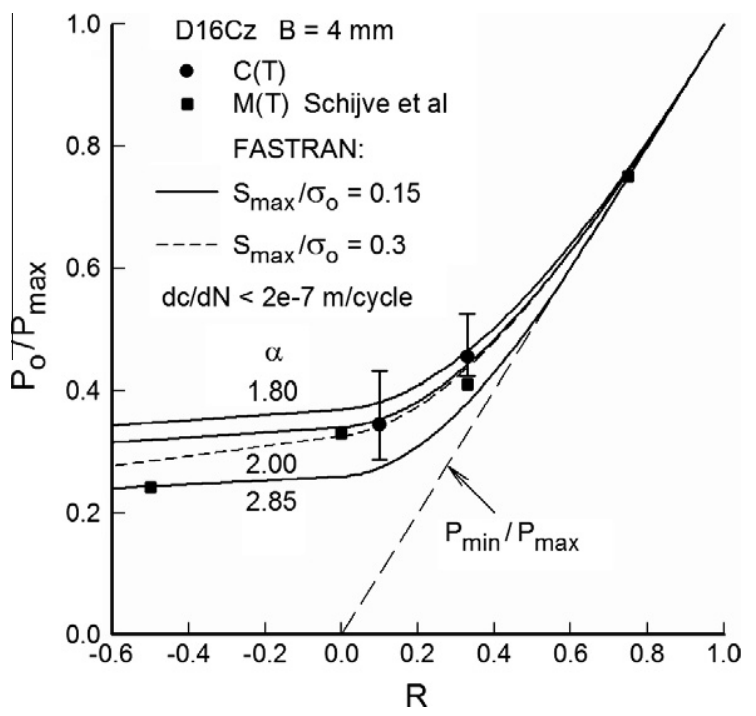

Fig. 6. Crack-opening load ratio as a function of stress ratio from CA tests.

circular symbols show the mean and scatter bands from several hundred data points at each $R$ value on the $C(T)$ specimens. The square symbols show the mean value of the crack-opening-load ratio evaluated on $M(T)$ test data at various $R$ values taken from Ref. [1]. At positive $R$ values, the results on both specimen types agreed fairly well.

The solid curves are calculated results [11] for various constraint factors at a low applied stress; and the dashed curve at $S_{\max } / \sigma_{\mathrm{o}}=0.3$ for $\alpha=2$. For low rates, a constraint factor of 2 matches the results quite well and will be used as the initial guess for the constraint factor. (A constraint factor of 2.85 was previously used by Skorupa et al. [3] in the evaluation of the NASGRO strip-yield model calculations. This value is very close to plane-strain conditions and would not cause as much crack-growth delay after an overload than $\alpha=2$.) But CA data alone is not sufficient to establish the proper constraint factors. Single-spike overload and/or repeated spike overload tests should be used to help determine the proper constraint factors $[12,13]$ by trial-and-error procedures. In the following, the $\Delta K_{\text {eff }}$-rate relation for the D16Cz aluminum alloy tested under laboratory air and room temperature conditions was developed from the $C(T)$ specimen data.

The data shown in Fig. 5 was analyzed with the crack-closure model and these results are shown in Fig. 7 for the $C(T)$

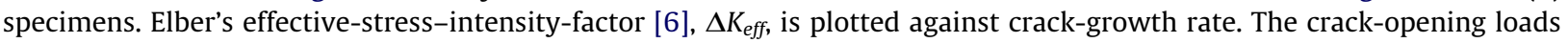
from the crack-closure model, FASTRAN, were used to correlate these data [11]. As previously mentioned, the constraint-loss 


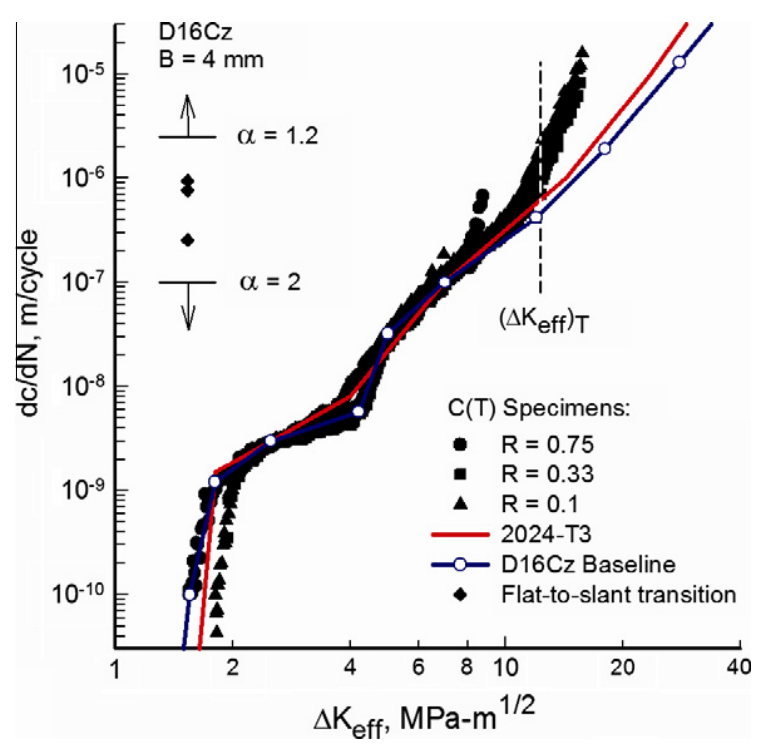

Fig. 7. Effective stress-intensity factor $\left(\Delta K_{\text {eff }}\right)$ against rate for $C(T)$ specimens.

regime has been associated with the transition from flat-to-slant crack growth. (However, a constraint loss can occur without the development of the flat-to-slant crack growth mechanism.) Examination of the $C(T)$ specimens, especially those under CA loading, identified the test specimens that developed single- or double-shear modes. The $R=0.1$ specimens ( 3 tests) developed single shear, while the $R=0.33$ specimens ( 2 tests) developed the double-shear mode. The single $R=0.75$ test had just begun to develop the double-shear mode, but then fractured under single shear. The diamond symbols show rate measurements made on $C(T)$ specimens where full-slant conditions were met. The dashed vertical line shows the calculated $\left(\Delta K_{\text {eff }}\right)_{T}$ value from Eq. (3) where the flat-to-slant crack-growth transition should occur for this sheet material. The rate location along the $\Delta K_{\text {eff }}$-rate curve agreed well with the measured rates (diamond symbols). Currently, the selection of the constraint factors and their associated rates, during the constraint-loss regime, has to be obtained by trial-and-error. It is, however, suspected that the start of the slant-crack growth regime is independent of sheet thickness and occurs as the plastic zone at the free surface begins to allow shear deformations. But the attainment of the fully slant-crack growth $\left(45^{\circ}\right)$ is a function of the sheet thickness. For crack-growth rates less than $1 \mathrm{e}-7 \mathrm{~m} /$ cycle, a constraint factor, $\alpha_{1}$, of 2 was used, but above a rate of $2.5 \mathrm{e}-6 \mathrm{~m} /$ cycle, a constraint factor, $\alpha_{2}$, of 1.2 was used. The compressive constraint factor, $\beta$, was assumed to be unity because a closed crack has no singular behavior. The crack-closure model correlated the fatigue-crack-growth rate data in a tight band over a wide range in rates. More scatter or variations were observed in the constraint-loss regime, near fracture, and in the near threshold regime.

In Fig. 7, the large open circles with the solid lines show the $\Delta K_{\text {eff }}$-rate baseline relation chosen to fit these data and used as the multi-linear (table-lookup) input, Eq. (4), in the FASTRAN code. The particular values are given in Table 1.

Table 1

Effective stress-intensity factor against rate relation for $\mathrm{D} 16 \mathrm{Cz}(B=4 \mathrm{~mm})$.

\begin{tabular}{ll}
\hline$\Delta K_{\text {eff }}\left(\mathrm{MPa} \mathrm{m}^{1 / 2}\right)$ & $d c / d N(\mathrm{~m} /$ cycle $)$ \\
\hline 1.45 & $1.0 \mathrm{e}-11$ \\
1.55 & $1.0 \mathrm{e}-10$ \\
1.80 & $1.2 \mathrm{e}-9$ \\
2.50 & $3.0 \mathrm{e}-9$ \\
4.20 & $5.7 \mathrm{e}-9$ \\
5.00 & $3.2 \mathrm{e}-8$ \\
7.00 & $1.0 \mathrm{e}-7$ \\
12.0 & $4.2 \mathrm{e}-7$ \\
18.0 & $1.9 \mathrm{e}-6$ \\
28.0 & $1.3 \mathrm{e}-5$ \\
48.0 & $1.5 \mathrm{e}-4$ \\
$\alpha_{1}=2.0$ & $1.0 \mathrm{e}-7$ \\
$\alpha_{2}=1.2$ & $2.5 \mathrm{e}-6$ \\
$\Delta K_{o}=0$ & $p=1$ \\
$K_{F}=250 \mathrm{MPa} \mathrm{m}^{1 / 2}$ & $m=1.0$ and $q=4$ \\
\hline
\end{tabular}




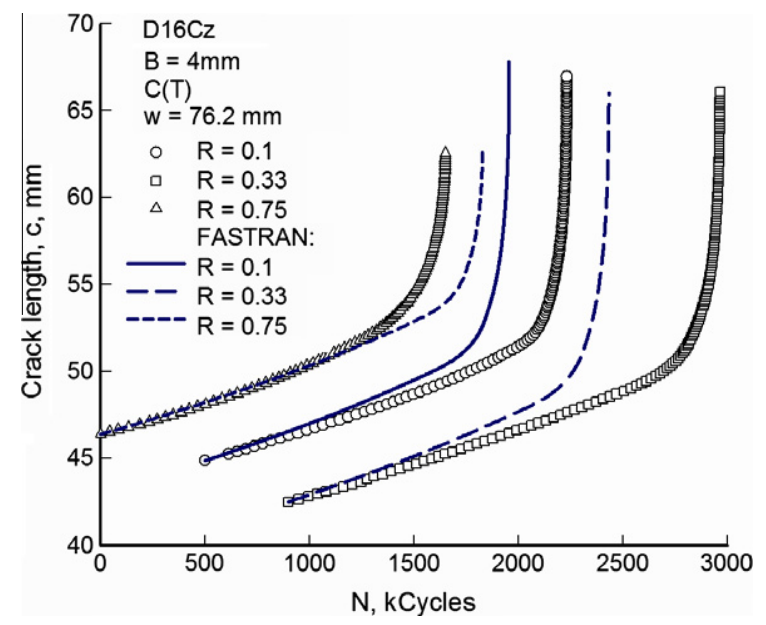

Fig. 8. Crack length against cycles for $C(T)$ specimens and model calculations under CA loading.

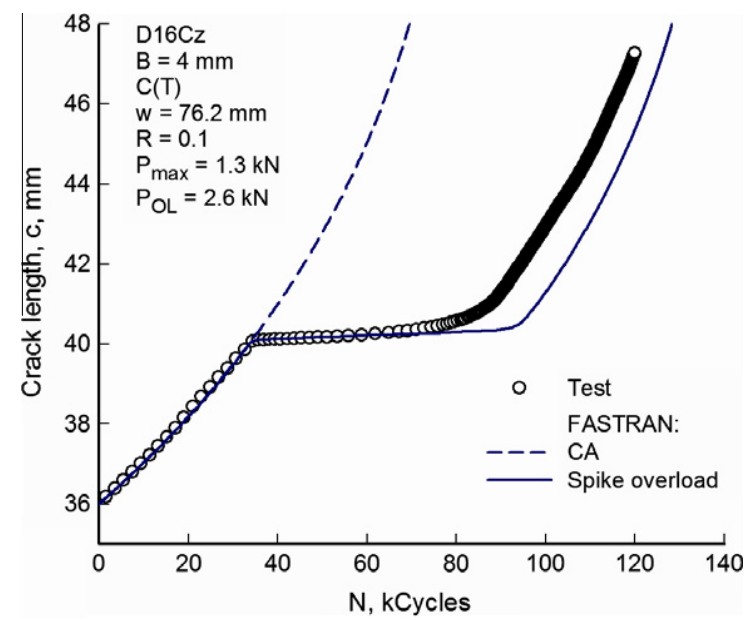

Fig. 9. Crack length against cycles for a $C(T)$ specimen and model calculations for a single-spike overload.

A comparison of calculated crack-length-against-cycles for the $C(T)$ specimens subjected to CA loading are shown in Fig. 8 . The test data are shown as symbols and the FASTRAN calculations are shown as curves. For clarity, the test data and curves have been offset in cycles to separate the curves. The sharp knees in the $C(T)$ curves correspond to the rapid change in rate behavior around $1 \mathrm{e}-8 \mathrm{~m} /$ cycle (see Fig. 7 ) on the $\Delta K_{\text {eff }}$-rate curve. The agreement between the tests and model calculations was within about $\pm 25 \%$. The largest discrepancy was on the $R=0.33$ test that had developed the double-shear crack-surface mode, instead of single-shear, and, consequently, produced a longer fatigue-crack growth life.

\section{Single-spike overload}

A single-spike overload test on a $C(T)$ specimen was used to help substantiate the selection of the constraint factors $(\alpha, \beta)$ in the crack-closure model. Fig. 9 shows a comparison between the OL test results and model calculations. For the $C(T)$ specimen, the model predicted the CA portion very well, but slightly over predicted the retardation. But the agreement between the model and test data was within $10 \%$ and demonstrated that the delayed retardation could be modeled very well, if the proper constraint factors are used.

\section{Spectrum loading}

As previously mentioned, the Mini-Falstaff sequence could not be applied to the $C(T)$ specimens, so a modified sequence was developed-Mini-Falstaff+. A dummy specimen was first used to checkout the variable-amplitude software and to determine test frame parameters to optimize the setting for the test machine and variable-amplitude software. Then two tests 


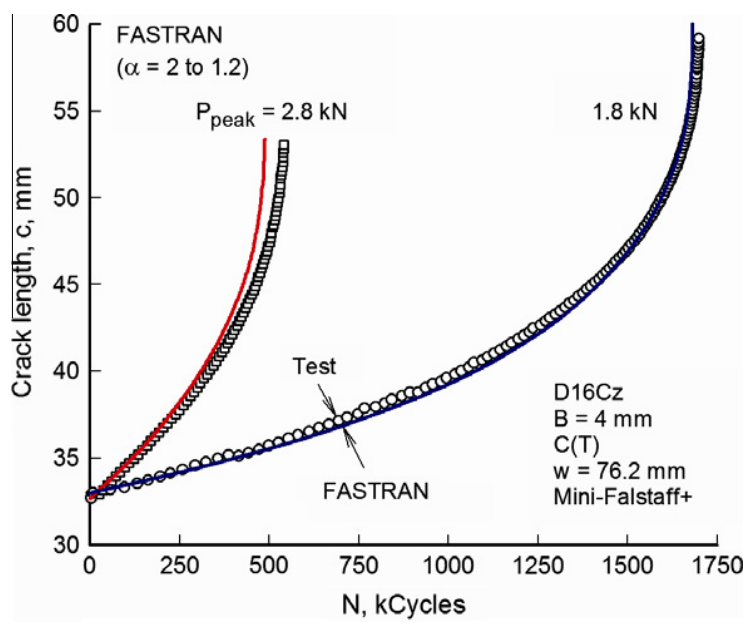

Fig. 10. Crack length against cycles for $C(T)$ specimens and model calculations for Mini-Falstaff + spectrum loading.

were conducted on the D16Cz alloy, one at a low load and another at a high load. The results from these two tests are shown in Fig. 10. In these tests, compression loading was initially applied $\left(K_{c p}=-23 \mathrm{MPa} \mathrm{m}^{1 / 2}\right)$ to start a small crack at the V-notch root and then the spectrum loading was applied. The solid curves are the predicted results from FASTRAN, which agreed very well with the tests (within 10\%).

\section{Discussion of results}

The test program conducted by Schijve et al. [1] on the D16Cz clad aluminum alloy, and used by Skorupa et al. [3] to assess the NASGRO strip-yield model options, produced results that were primarily in the "constraint-loss regime", which is a difficult region because of the uncertainties in the constraint factors and the proximity of fracture conditions. The test program conducted herein on $C(T)$ specimens made of the same exact material generated fatigue-crack-growth-rate data from threshold to near fracture for stress ratios of $0.1,0.33$ and 0.75 . The CA test data from the $M(T)$ and $C(T)$ specimens for the same stress ratio agreed very well. Some differences were observed in the fracture region because linear-elastic stressintensity-factors do not correlate fracture conditions. Thus, a Two-Parameter Fracture Criterion (TPFC) was used to help model fatigue-crack growth as the cracks grew to failure. The TPFC tended to work well on both specimen types (tension and bending) using the same fracture constants $\left(K_{F}\right.$ and $\left.m\right)$.

As the cracks grew to failure under cyclic loading, it was observed that the $R=0.33$ tests tended to show more doubleshear fatigue surfaces than the other tests at $R=0$ and 0.75 , which tended to develop single shear (slant) fatigue surfaces. This change in failure mode has also been associated with the constraint-loss regime. In other studies, it had also been observed that double-shear failure modes promote slower crack growth and higher fracture toughness. This may explain some of the under predictions made with the strip-yield model for the $R=0.33$ loading.

A rapid rise in rate behavior was observed between the lower and upper plateaus around $1 \mathrm{e}-8 \mathrm{~m} / \mathrm{cycle}$. A few data points in the early stages of fatigue-crack growth in the $M(T)$ specimens tended to match the rapid-rise region observed in the $C(T)$ specimens. The slope of the data in this region appeared to be the same for the two low $R$-values ( 4 tests), but the $R=0.75$ results (one test) exhibited a slightly lower slope. A difference was also observed in the threshold region for the $\Delta K_{\text {eff }}$-rate data with the two low $R$ ratio results agreeing and producing a slightly higher threshold (17\%) than the $R=0.75$ test results. However, the high- $R$ results were selected in the multi-linear (table-lookup) method to model the threshold behavior. Overall, the CA data correlated very well between both specimen types over a wide range in rates and stress ratios.

The single-spike overload test and the spectrum tests on the $C(T)$ specimens demonstrated that retardation and acceleration behavior could be accurately modeled with the strip-yield model once proper constraint factors were selected and the constraint-loss regime established.

\section{Concluding remarks}

Fatigue-crack-growth tests have been conducted on $C(T)$ specimens made of D16Cz clad aluminum alloy (4 mm thick). Middle-crack-tension, $M(T)$, specimen data on the same material was obtained from the literature. Constant-amplitude (CA) loading and single-spike overload (OL) tests were used to help establish the constraint factor variations for this material and thickness; and the effective-stress-intensity-factor-range-against-rate relation was developed. Using the FASTRAN lifeprediction code (strip-yield model), crack-growth behavior was either calculated for CA and OL cases or predicted for spectrum loading. In general, the model calculations were within $\pm 25 \%$ of the CA test results. Some of these discrepancies may be 
due to the development of double-shear crack-growth behavior in some of the high-R tests, which generally causes slower crack growth than single-shear cases. Model predictions under the single-spike overload and spectrum tests on the $C(T)$ specimens were well within $10 \%$ of the test data.

\section{Acknowledgements}

The authors thank Professors M. Skorupa, T. Machniewicz and J. Schijve for providing the D16Cz alloy and the test data on the $M(T)$ specimens. The US Army under a sub-contract through Georgia Tech (Dr. A. Makeev) to Mississippi State University (MSU) sponsored this study. Special thanks to Dr. Dy Le, US Army (formally US Federal Aviation Administration), for continuing to support development of the compression pre-cracking testing procedures used in this study; and to Dr. Keith Donald, Fracture Technology Associates, for his valuable advise on his steady-state and variable-amplitude fatigue-crack-growth software.

\section{References}

[1] Schijve J, Skorupa M, Skorupa A, Machniewicz T, Gruszczynski P. Fatigue crack growth in the aluminum alloy D16 under constant and variable amplitude loading. Int J Fatigue 2004;26:1-15.

[2] NASGRO reference Manual (version 4.02). Southwest Research Institute and NASA Johnson Space Center; 2002.

[3] Skorupa M, Machniewicz T, Schijve J, Skorupa A. Application of the strip-yield model from the NASGRO software to predict fatigue crack growth in aluminum alloys under constant and variable amplitude loading. Engng Fract Mech 2007;74:291-313.

[4] de Koning AU, ten Hoeve HJ, Henriksen TK. Description of crack growth using the strip-yield model for computation of crack opening loads, crack tip stretch, and strain rates. ASTM STP 1343, West Conshohocken, PA; 1999. p. 459-74.

[5] Newman Jr JC. FASTRAN-II - a fatigue crack growth structural analysis program. NASA TM 104159; 1992.

[6] Elber W. The significance of fatigue crack closure. ASTM STP 486; 1971. p. 230-42.

[7] Dugdale DS. Yielding of steel sheets containing slits. J Mech Phys Solids 1960;8:100-4.

[8] FALSTAFF-a description of flight aircraft standard for fatigue evaluation, combined report of F\&W (Switzerland), LBF (Darmstadt), NLR (Amsterdam) and IABG (Munich); 1976.

[9] Murakami Y, editor. The rainflow method in fatigue, international symposium on fatigue damage measurement and evaluation under complex loadings, Fukuoka, Japan; 1991.

[10] Newman Jr JC. A crack-closure model for predicting fatigue crack growth under aircraft spectrum loading. ASTM STP 748; 1981. p. 53-84.

[11] Newman Jr JC. A crack opening stress equation for fatigue crack growth. Int J Fract 1984;24:R131-5.

[12] Newman Jr JC, Dawicke DS. Prediction of fatigue crack growth in a high-strength aluminum alloy under variable-amplitude loading. Adv Fract Res ICF7;1989. p. 945-52.

[13] Newman Jr JC. Prediction of crack growth under variable-amplitude loading in various materials. In: International conference on engineering against fatigue, Sheffield, United Kingdom; 1997. p. 261-268.

[14] Newman Jr JC. Effects of constraint on crack growth under aircraft spectrum loading. In: Beukers A, et al. editors. Fatigue of Aircraft Materials Delft University Press; 1992 . p. 83-109.

[15] Schijve, J. Significance of fatigue cracks in micro-range and macro-range. ASTM STP 415, Philadelphia, PA; 1967. p. $415-59$.

[16] Schijve J. Shear lips on fatigue fractures in aluminum sheet material. Engng Fract Mech 1981;14:789-800.

[17] Ziegler B, Yamada Y, Newman Jr JC. Application of a strip-yield model to predict crack growth under variable-amplitude and spectrum loading - Part 2: middle-crack-tension specimens. Engng Fract Mech [this volume].

[18] Newman Jr JC, Schneider J, Daniel A, McKnight D. Compression pre-cracking to generate near threshold fatigue-crack-growth rates in two aluminum alloys. Int J Fatigue 2005;27:1432-40.

[19] Ruschau JJ, Newman Jr JC. Compression precracking to generate near threshold fatigue-crack-growth rates in an aluminum and titanium alloy. J ASTM Int 2008;5(7).

[20] Yamada Y, Newman III JC, Newman Jr JC. Elastic-plastic finite-element analyses of compression precracking and its influence on subsequent fatiguecrack growth. J ASTM Int 2008;5(8).

[21] Newman Jr JC, Yamada Y. Compression precracking methods to generate near-threshold fatigue-crack-growth-rate data. Int J Fatigue 2010;32:879-85.

[22] ASTM standard test method for measurement of fatigue crack growth rates. ASTM E-647; 2006 . p. 615-57.

[23] McClung RC. Finite-element analysis of specimen geometry effects on fatigue crack closure. Fatigue Fract Engng Mater Struct 1994;17:861-72.

[24] Yamada Y, Newman Jr JC. Crack closure behavior of 2324-T39 aluminum alloy near threshold conditions for high load ratio and constant $K_{\text {max }}$ tests. Int J Fatigue 2009;31:1780-7.

[25] Newman Jr JC. Fracture analysis of various cracked configurations in sheet and plate materials. ASTM STP 605, Philadelphia, PA; 1976. p. 104-23. 